\title{
QUEEN'S
UNIVERSITY
BELFAST
}

\section{Ethanol $(\mathrm{C} 2 \mathrm{H} 5 \mathrm{OH})$ spray of sub-micron droplets for laser driven negative ion source}

Prasad, R., Borghesi, M., Abicht, F., Nickles, P. V., Stiel, H., Schnürer, M., \& Ter-Avetisyan, S. (2012). Ethanol $\left(\mathrm{C}_{2} \mathrm{H}_{5} \mathrm{OH}\right)$ spray of sub-micron droplets for laser driven negative ion source. Review of Scientific Instruments, 83(8), [083301]. https://doi.org/10.1063/1.4747002

Published in:

Review of Scientific Instruments

Document Version:

Publisher's PDF, also known as Version of record

Queen's University Belfast - Research Portal:

Link to publication record in Queen's University Belfast Research Portal

\section{Publisher rights}

Copyright 2012 American Institute of Physics. This article may be downloaded for personal use only. Any other use requires prior permission of the author and the American Institute of Physics.

The following article appeared in Rev. Sci. Instrum. 83, 083301 (2012) and may be found at http://scitation.aip.org/content/aip/journal/rsi/83/8/10.1063/1.4747002

\section{General rights}

Copyright for the publications made accessible via the Queen's University Belfast Research Portal is retained by the author(s) and / or other copyright owners and it is a condition of accessing these publications that users recognise and abide by the legal requirements associated with these rights.

\section{Take down policy}

The Research Portal is Queen's institutional repository that provides access to Queen's research output. Every effort has been made to ensure that content in the Research Portal does not infringe any person's rights, or applicable UK laws. If you discover content in the Research Portal that you believe breaches copyright or violates any law, please contact openaccess@qub.ac.uk. 


\section{AIP Scientific Instruments}

\section{Ethanol $(\mathrm{C} 2 \mathrm{H} 5 \mathrm{OH})$ spray of sub-micron droplets for laser driven negative ion source}

R. Prasad, M. Borghesi, F. Abicht, P. V. Nickles, H. Stiel et al.

Citation: Rev. Sci. Instrum. 83, 083301 (2012); doi: 10.1063/1.4747002

View online: http://dx.doi.org/10.1063/1.4747002

View Table of Contents: http://rsi.aip.org/resource/1/RSINAK/v83/i8

Published by the American Institute of Physics.

\section{Related Articles}

Dynamical behavior of electrified pendant drops

Phys. Fluids 25, 012104 (2013)

A novel method to produce small droplets from large nozzles

Rev. Sci. Instrum. 83, 115105 (2012)

The buoyancy-driven motion of a single skirted bubble or drop rising through a viscous liquid

Phys. Fluids 24, 112101 (2012)

Effects of fluid properties and laser fluence on jet formation during laser direct writing of glycerol solution J. Appl. Phys. 112, 083105 (2012)

Numerical simulation of drop deformations and breakup modes caused by direct current electric fields Phys. Fluids 24, 102101 (2012)

\section{Additional information on Rev. Sci. Instrum.}

Journal Homepage: http://rsi.aip.org

Journal Information: http://rsi.aip.org/about/about_the_journal

Top downloads: http://rsi.aip.org/features/most_downloaded

Information for Authors: http://rsi.aip.org/authors

\section{ADVERTISEMENT}

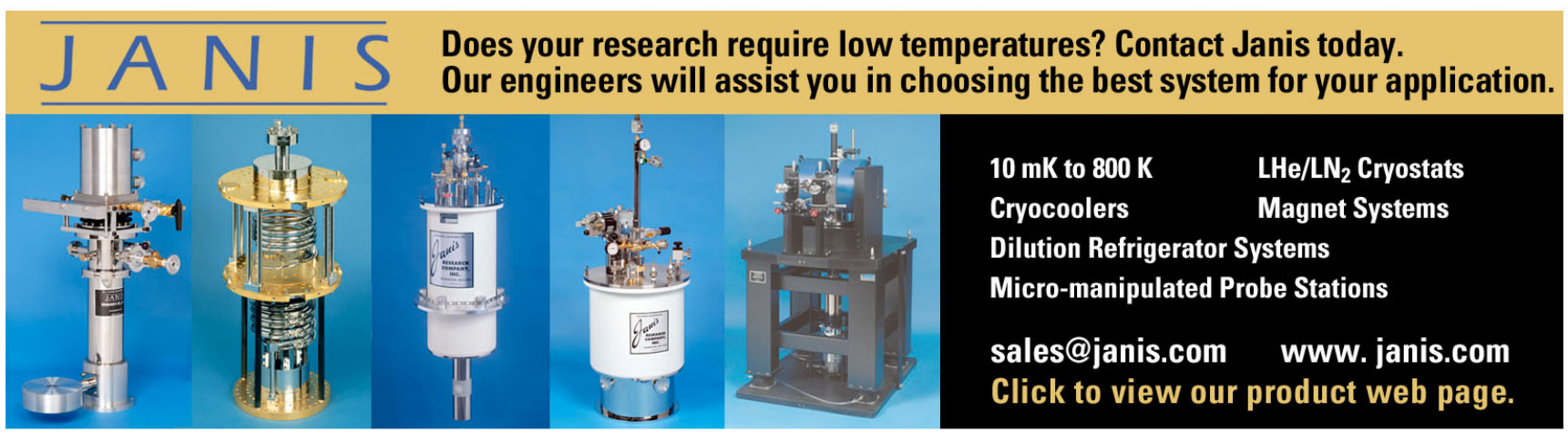




\title{
Ethanol $\left(\mathrm{C}_{2} \mathrm{H}_{5} \mathrm{OH}\right)$ spray of sub-micron droplets for laser driven negative ion source
}

\author{
R. Prasad, ${ }^{1}$ M. Borghesi, ${ }^{1}$ F. Abicht, ${ }^{2}$ P. V. Nickles, ${ }^{3}$ H. Stiel, ${ }^{2}$ M. Schnürer, ${ }^{2}$ \\ and S. Ter-Avetisyan ${ }^{1,4, a)}$ \\ ${ }^{1}$ Centre for Plasma Physics, School of Mathematics and Physics, The Queen's University, \\ BT7 1NN Belfast, United Kingdom \\ ${ }^{2}$ Max Born Institute, Nonlinear Optics and Short Pulse Spectroscopy, 12489 Berlin, Germany \\ ${ }^{3}$ WCU, Gwangju Institute of Science and Technology 1, Oryong-dong, Buk-gu, Gwangju 500-712, South Korea \\ ${ }^{4}$ ELI - Extreme Light Infrastructure, Institute of Physics, 18221 Prague, Czech Republic
}

(Received 3 June 2012; accepted 6 August 2012; published online 30 August 2012)

Liquid ethanol $\left(\mathrm{C}_{2} \mathrm{H}_{5} \mathrm{OH}\right)$ was used to generate a spray of sub-micron droplets. Sprays with different nozzle geometries have been tested and characterised using Mie scattering to find scaling properties and to generate droplets with different diameters within the spray. Nozzles having throat diameters of $470 \mu \mathrm{m}$ and $560 \mu \mathrm{m}$ showed generation of ethanol spray with droplet diameters of $(180 \pm 10) \mathrm{nm}$ and $(140 \pm 10) \mathrm{nm}$, respectively. These investigations were motivated by the observation of copious negative ions from these target systems, e.g., negative oxygen and carbon ions measured from water and ethanol sprays irradiated with ultra-intense $\left(5 \times 10^{19} \mathrm{~W} / \mathrm{cm}^{2}\right)$, ultra short $(40 \mathrm{fs})$ laser pulses. It is shown that the droplet diameter and the average atomic density of the spray have a significant effect on the numbers and energies of accelerated ions, both positive and negative. These targets open new possibilities for the creation of efficient and compact sources of different negative ion species. (C) 2012 American Institute of Physics. [http://dx.doi.org/10.1063/1.4747002]

\section{INTRODUCTION}

In numerous laser-plasma experiments, the interaction of high intensity laser pulses with different types of targets has been explored: solids, gases, as well as atomic and molecular cluster targets (diameter up to tens of $\mathrm{nm}$ ) with average atomic density above $10^{19} \mathrm{~cm}^{-3} .{ }^{1}$ When the cluster size becomes as large as hundreds of $\mathrm{nm}$, one can expect interesting effects to arise as compared to a massive solid target or a cluster target. These "larger clusters" can already be considered as droplets and the whole target a spray of droplets. In consideration of the solid density of the individual droplet, and additionally, since the scale length of the droplets is smaller or comparable than the wavelength of the incident laser beam, direct heating of the whole target particle is possible, as in clusters.

These targets have been studied less extensively than other types, which is likely due to the lack of easy and reliable technical solutions to obtain high-density sub-micron particle spray. For example, smaller droplets with a diameter of $0.6 \mu \mathrm{m}$ have been obtained by splitting the droplet ensemble electrostatically, ${ }^{2}$ however the average atomic density was significantly reduced (up to $10^{16} \mathrm{~cm}^{-3}$ ).

A new spray generator ${ }^{3,4}$ was developed to produce a plume of sub-micron size droplets from liquids. A water spray in laser-plasma experiments with constituents of submicron size $(\sim 150 \mathrm{~nm})$ and relatively high average atomic density $\left(>10^{18} \mathrm{~cm}^{-3}\right)$ allowed to explore an almost unknown regime of laser matter interaction closing the gap between the solid and gaseous or cluster targets. In fact, novel features have been observed when the water spray was irradiated with short (45 fs) and high contrast $\left(10^{-8}\right)$ laser pulses

a) Electronic mail: sargis.ter-avetisyan@eli-beams.eu. at an intensity $\sim 5 \times 10^{19} \mathrm{~W} / \mathrm{cm}^{2}$. It was found that this almost debris free target can be a more efficient source of hard $\mathrm{x}$-rays ${ }^{4}$ and neutrons ${ }^{5}$ than cluster targets; quasi monoenergetic proton emission with energy $(1.6 \pm 0.08) \mathrm{MeV}$ (Ref. 6) was also measured from the spray, which may open up new perspectives in laser matter interactions studies and applications, e.g., as a source for post acceleration and beam transport in compact $\mathrm{MeV}$ accelerators. ${ }^{7}$ Very recently, it was found that the water spray is also an abundant source of $\mathrm{MeV}$ negative oxygen ions. ${ }^{8}$ Model calculations and simulations of these experimental findings suggest even more effective laser energy transfer to the target, and accordingly higher proton energy and flux, if droplet size and average particle density could be increased. Additionally, the accelerated proton beam will become more directional when droplet size is increased (e.g., under the same interaction conditions 20\%-25\% larger droplets led to a two-fold increase in energy of the accelerated mono-energetic proton beam accelerated in the laser propagation direction ${ }^{9}$ ).

However, in these experiments, the single droplet diameter in the spray was unchanged because even a detailed characterisation of the water spray ${ }^{3,4}$ could not reveal the parameters responsible for the spray density and droplet diameter. In the conventional approach (i.e. growing gas clusters from an expanding nozzle flow with the appropriate set of flow field conditions, characterised by a condensation scaling parameter $\Gamma^{*},{ }^{10}$ ) the water spray has shown not to follow a similar condensation description, which could have allowed to predict the cluster size and average density under given experimental conditions (nozzle geometry, backing pressure).

To overcome these limitations and inspired by experimental findings and theoretical predictions, we have looked once more to the spray characteristics for different nozzle 
geometries and condensation conditions with the aim to generate sprays with controllable droplet size. Additionally, the spray of a different liquid than water was investigated with the idea that it might lead to new, unexplored properties in the forthcoming experiments.

In this article, we report on the generation of a spray of ethanol $\left(\mathrm{C}_{2} \mathrm{H}_{5} \mathrm{OH}\right)$ with adjustable droplet size. Employing the Mie scattering technique, it was found that the size of the droplets in the spray could be changed by varying the size of the throat diameter of the hypersonic nozzle. Indeed, the laser-plasma interaction experiments have revealed the critical importance of the single droplet size and the average density of the spray to the acceleration of mono-energetic proton and negative ion beams.

\section{EXPERIMENTAL METHODS}

\section{A. Spray generator}

A spray is formed by adiabatic expansion of superheated vapour through the hypersonic nozzle into a vacuum. ${ }^{11}$ It comprises of a solenoid driven pulsed valve (from Parker Hannifin Company), a heated channel, and a hypersonic conical nozzle (Fig. 1). For target optimization and system synchronization, the spray is pulsed by an electromagnetic valve for every $6 \mathrm{~s}$ with a pulse duration of $2 \mathrm{~ms}$, which keeps the background pressure before each spray pulse on a $10^{-5}$ mbars level.

Ethanol $(99.9 \% \mathrm{v} / \mathrm{v})$ with 25 bars backing pressure is injected upon opening of the valve into the heated channel that is $1 \mathrm{~mm}$ in diameter and $15 \mathrm{~mm}$ in length at a temperature of up to $140{ }^{\circ} \mathrm{C}$ (Fig. 1). Though the heater is in direct thermal contact with the channel, a 9 mm Polypenco PEEK 450G insulator is used to separate it from the valve in order to keep the temperature of the liquid inside the valve below the boiling temperature. The injected liquid is vaporized in the heating channel and a superheated vapour under high pressure is formed. The latter expands through a hypersonic nozzle, with $8 \mathrm{~mm}$ long conical section and $2=7^{\circ}$ opening angle, into a vacuum and forms a spray of a sub-micron liquid droplets.

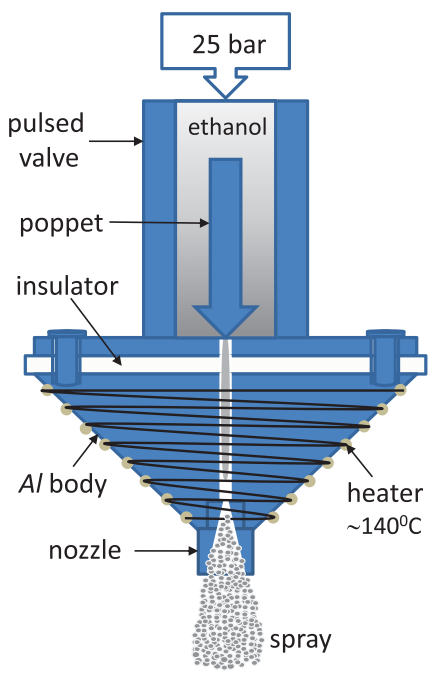

FIG. 1. Spray generator.

\section{B. Droplet size characterisation}

The scattering of electromagnetic radiation by spherical particles, Mie scattering, was employed to analyze the droplet size in the spray. ${ }^{12-14}$ The scattering intensity of a linearly polarised monochromatic wave by an ensemble of homogeneous spheres of arbitrary refractive index in a volume $V_{0}$ is given by

$$
I_{\perp}(\theta)=V_{0} \int_{0}^{\infty} I_{0 \perp}(\theta, \alpha(N)) f(N) d N
$$

where $I_{0 \perp}$ is the scattering intensity for a single particle when the polarisation of the incident wave is perpendicular to the scattering plane, $\theta$ is the scattering angle $\left(\theta=180^{\circ}\right.$, i.e., forward scattering, measured from the incident laser beam), and $N$ is the total number of particles occupied within volume $V_{0}$ with a particle size distribution function $f(N)$. The size parameter $\alpha(N)=\frac{2 \pi a(N)}{\lambda}$ depends on the radius of the sphere $a$ (also called Mie radius) and the laser wavelength $\lambda$. The single particle scattering intensity $I_{0 \perp}$ is given by

$$
I_{0 \perp}(\theta, \alpha(N))=\left(\frac{\lambda}{2 \pi R}\right)^{2} I_{0} i_{\perp}(\theta, \alpha(N)),
$$

where $R$ is the distance between scattering volume and detector plane, $I_{0}$ is the incident intensity, and $i_{\perp} \equiv i_{\perp} / \alpha^{3}$. Generally, the tabulated value of the function $i_{\perp}(\theta, \alpha(N))$ (i.e., square of amplitude function, cf. e.g., Ref. 14) for different refractive indices is available ${ }^{15,16}$ and can be used directly to fit theoretically Mie scattering curves to the measured data in order to infer the particle size. However, for liquid ethanol which has a refractive index $m=1.36, i_{\perp}$ was not tabulated in the available literatures. A routine in MATLAB was developed (following the description in Ref. 16 chapter 4) to calculate the value of $i_{\perp}$ for different refractive indices and for different $\theta$ and $\alpha$ values up to a precision of 14 significant digits. The tabulated values of $i_{\perp}{ }^{15,16}$ were well reproduced by our routine. The new values of $i_{\perp}$ for $m=1.36$ have been tabulated in the Appendix.

The ethanol spray was probed with three different laser wavelengths namely $337 \mathrm{~nm}, 450 \mathrm{~nm}$, and $500 \mathrm{~nm}$ with a beam diameter of $\sim 1 \mathrm{~mm}$. A glass fibre was mounted on a rotating stage to collect the scattered signal at various angular positions. The acceptance diameter of the fibre aperture was $3 \mathrm{~mm}$ and the detection radius around the vertical axis of the nozzle was $13.5 \mathrm{~mm}$ corresponding to a $39 \mathrm{msr}$ solid angle. The other end of the optical fibre was coupled to a sensitive photomultiplier tube (PMT) for signal detection (Hamamatsu R928). The scattered signal was measured from $40^{\circ}$ up to $135^{\circ}$ with respect to the diagnostic beam axis with a step of $10^{\circ}$. Two nozzles with diameters of $470 \mu \mathrm{m}$ and $560 \mu \mathrm{m}$ have been used.

\section{RESULTS AND DISCUSSION}

The measurements with a $337 \mathrm{~nm}$ probing wavelength were taken at two different temperatures of the heating channel: $110{ }^{\circ} \mathrm{C}$ and $140{ }^{\circ} \mathrm{C}$ and at three different positions, one very close to the tip of the nozzle $(\mathrm{z} \sim 1 \mathrm{~mm}), 5 \mathrm{~mm}$, and $10 \mathrm{~mm}$ below the nozzle tip assuming that the size of the 

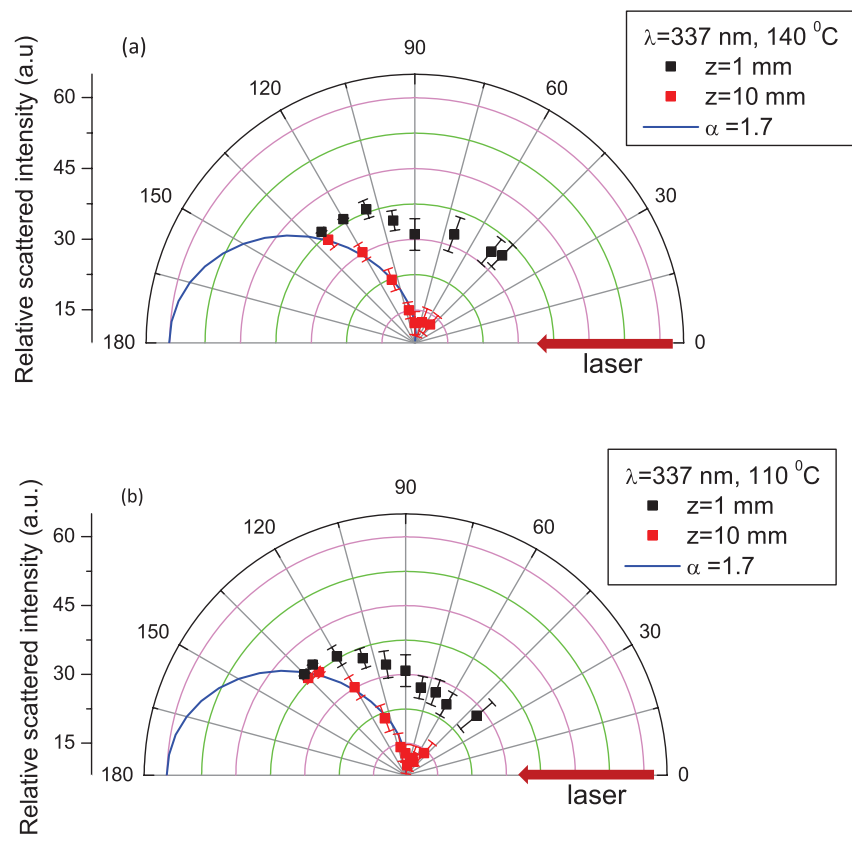

FIG. 2. Spatial distribution of the scattered light of the $337 \mathrm{~nm}$ probe beam from the ethanol spray, plotted on a polar graph for a nozzle diameter of $470 \mu \mathrm{m}$. The signal is measured at 1 and $10 \mathrm{~mm}$ distances from the nozzle (a) at a temperature of the Al-body of $110^{\circ} \mathrm{C}$ and (b) at $140^{\circ} \mathrm{C}$. Solid lines are the fits obtained using tabulated value of $i_{\perp}$ from Table I.

droplets is not changing. Indeed, since the droplets are formed during adiabatic expansion of superheated vapour into a vacuum, they are cool and there is no evaporative mass loss, and, since the density of the particles decreases exponentially with the distance (see Fig. 3 in Ref. 4), their growth rate or droplet diameter change is negligible.

In Fig. 2 the spatial distribution of the scattered light for a nozzle diameter of $470 \mu \mathrm{m}$, is plotted on a polar graph. Figure 2(a) shows the angular dependence of the scattered signal at a temperature of $110{ }^{\circ} \mathrm{C}$ and Fig. 2(b), at $140{ }^{\circ} \mathrm{C}$. Each data point represents the average of at least 10 recorded scattered signals at each angular position. The error bars assigned to the data points are the standard deviation of the signal fluctuation. The background signal, e.g., signal generated by the beam free propagation through the chamber when the spray is off, was practically zero for all the measurements.

It can be seen from the Fig. 2 that the signal near the nozzle tip $(\mathrm{z}=1 \mathrm{~mm})$ is smoother than the signal taken at $10 \mathrm{~mm}$ below the nozzle tip. This is mainly due to the large number of particles inside the scattering volume causing multiple scattering and smoothing of the signal pattern. At the distance of $5 \mathrm{~mm}$ from the nozzle tip, one still observes the contribution of multiple scattered signal into the measured scattering pattern (not shown in Fig. 2 in order to not overcomplicate the figure). However, the density of the particles decreases exponentially with the distance (see Fig. 3 in Ref. 4) and at $\mathrm{z}=10 \mathrm{~mm}$ below the nozzle, the single particle scattering events dominate the scattering signal. Further increase of the distance from the nozzle gradually leads to a decrease in the measured scattered signal, while the error bar of the measurements is increasing due to the spray density decrease. We have used the tabulated value of $i_{\perp}$ to fit the experimental data for the position $\mathrm{z}=10 \mathrm{~mm}$. For a size parameter $\alpha=1.7$, the experimental points were well fitted for both temperatures of the heating channel (cf. Fig. 2). The particle size was additionally confirmed by using two other probing laser wavelengths, viz. $450 \mathrm{~nm}$ and $500 \mathrm{~nm}$. Thus, different temperatures of the heating channel did not affect the droplet size, and at temperatures $110{ }^{\circ} \mathrm{C}$ and $140{ }^{\circ} \mathrm{C}$, the same particle size $(180$ $\pm 10) \mathrm{nm}$ was inferred from the measurement. The droplet size uncertainty was determined by the range of size parameter $\alpha$ over which the experimental data still can be fitted. It might be worth to notice that in Fig. 2, there is a small scattered signal also in the backward direction, which could also be due to multiple scattering or to incoherent scattering effects. ${ }^{14}$ Hence, the size of the ethanol droplets is different than in previous measurements of water droplets in the spray (droplet size $\sim 150 \mathrm{~nm}^{4}$ ) in spite that the same nozzle is used. Additionally, since in order to avoid multiple scattering, the measurements have been done at $\mathrm{z}=10 \mathrm{~mm}$ far from the nozzle, the data suggests $\sim 5$ times higher ethanol droplet density than with water according to Fig. 2 in Ref. 4.

The same measurements with a nozzle of $560 \mu \mathrm{m}$ diameter also show interesting results. For two different temperatures, $110^{\circ} \mathrm{C}$ and $140{ }^{\circ} \mathrm{C}$, the size of particles does not change as for the $470 \mu \mathrm{m}$ nozzle. In Fig. 3 the angular distribution of scattered intensity of the probe light, at $337 \mathrm{~nm}$ wavelength, and a detector position $\mathrm{z}=1 \mathrm{~mm}$ from the nozzle is shown. At both $110^{\circ} \mathrm{C}$ and $140^{\circ} \mathrm{C}$, the size parameter $\alpha$ $=1.3$, which corresponds to a droplet size of $140 \mathrm{~nm}$, fits very well the experimental data. In previous measurements using water the typical Mie scattering pattern was also detected at $\mathrm{z}$ $=1 \mathrm{~mm}$ below the nozzle, but employing a $470 \mu \mathrm{m}$ diameter nozzle. This suggests that for a nozzle diameter of $560 \mu \mathrm{m}$, the ethanol spray has a similar droplet density as the water spray (see Fig. 3 in Ref. 4) with nozzle diameter $470 \mu \mathrm{m}$.

To sum up: with $470 \mu \mathrm{m}$ and $560 \mu \mathrm{m}$ nozzles the size of the droplets in the ethanol spray is different: $(180 \pm 10)$ $\mathrm{nm}$ and $(140 \pm 10) \mathrm{nm}$, correspondingly, however the particle size is not changing at two different temperatures of the heating channel: $110^{\circ} \mathrm{C}$ and $140{ }^{\circ} \mathrm{C}$. It is worth mentioning, that with both nozzles, similar to the droplets in the water spray, ${ }^{4}$ the size distribution is very narrow (about $\pm 5 \%$ ). Additionally, in the case of the $470 \mu \mathrm{m}$ nozzle, according to Fig. 3 in

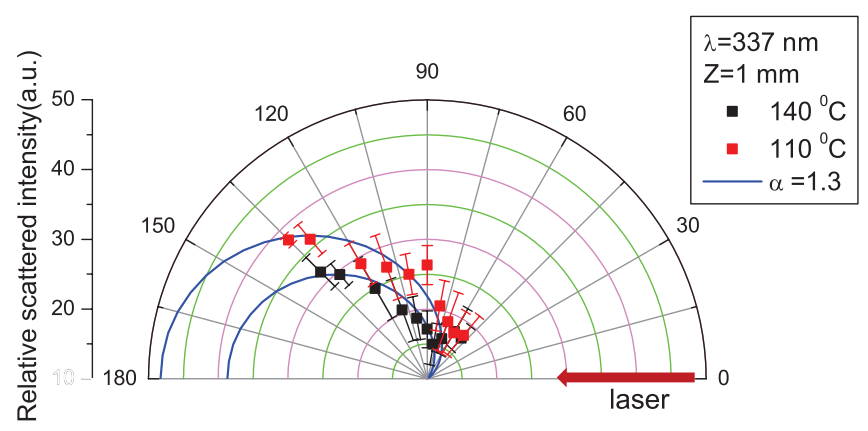

FIG. 3. Spatial distribution of the scattered light of the $337 \mathrm{~nm}$ probe beam from the ethanol spray is plotted on a polar graph at the nozzle diameter of $560 \mu \mathrm{m}$. Signal is measured $1 \mathrm{~mm}$ far from the nozzle (a) at a temperature of the Al-body of $110{ }^{\circ} \mathrm{C}$ and (b) at $140{ }^{\circ} \mathrm{C}$. Solid lines are the fits obtained using tabulated value of $i_{\perp}$ from Table I. 
Ref. 4 , there are five times more particles in a given scattering volume than with the $560 \mu \mathrm{m}$ nozzle, which has similar particle density to the water spray.

\section{NEGATIVE ION SOURCE}

Laser plasma interaction experiments with a water spray target have revealed a novel feature, namely the capability to generate negative ions. The experiments were carried out with the 30 TW -Ti: Sapphire system at the MaxBorn Institute, Berlin. When a water spray generated by our spray generator ${ }^{4}$ (droplets diameter $150 \pm 10 \mathrm{~nm}$ ) was irradiated with ultra-intense $\left(5 \times 10^{19} \mathrm{~W} / \mathrm{cm}^{2}\right)$, ultra-short $(45$ fs), and high-contrast (below $10^{-8}$ at $\sim 10$ ps prior the main peak) laser pulses, stable, and reproducible emission of copious negative oxygen ions was observed. Here, we mention the few aspects of this experiment which motivated our ethanol spray investigation. A detailed discussion was published elsewhere. ${ }^{8}$

In Fig. 4, typical spectra of accelerated ions from a water spray measured with a Thomson parabola spectrometer transversely to the laser propagation direction are shown. Here, only $\mathrm{O}^{1-}$ and $\mathrm{O}^{1+}$ ions have been detected on the absolutely calibrated micro-channel-plate (MCP) detector. When the laser pulse was temporally and spatially well inside the water spray, it insured stable and reproducible acceleration of $\mathrm{O}^{1-}$ and $\mathrm{O}^{1+}$ ions. It should be noticed that protons were not detected, which is likely due to their energies being below the spectrometer energy range (150 keV is the lower energy cut-off on the MCP detector, which is due to its limited size and the geometry of the spectrometer, chosen to provide high energy resolution: $\Delta \mathrm{E} / \mathrm{E} \sim 0.02$ ).

The spectra of ions accelerated in the lateral direction from the ethanol spray, under similar irradiation conditions are shown in Fig. 5. Here, besides the $\mathrm{O}^{1+}$ and $\mathrm{O}^{1-}$ ions (Fig. 5(a)), one can identify another negative ion species as $\mathrm{C}^{1-}$ together with $\mathrm{C}^{1+}$ and $\mathrm{C}^{2+}$ (Fig. 5(b)). Additionally, protons with $\mathrm{MeV}$ energies are appearing on the detector screen.

In general, the spectra of oxygen ions accelerated from water and ethanol sprays are different in terms of both their energy and number. In ethanol spray the number of $\mathrm{O}^{1+}$ and

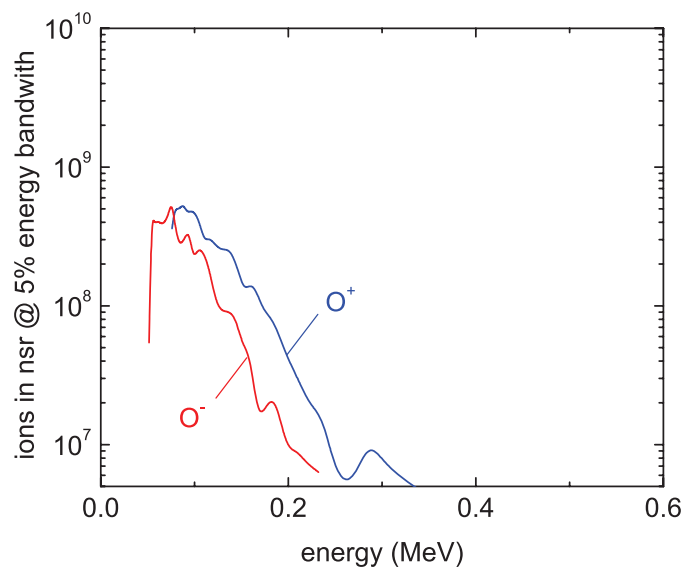

FIG. 4. Negative and positive oxygen ion spectra accelerated from water spray target, obtained from the digital CCD image of MCP-detector screen of the Thomson parabola spectrometer.
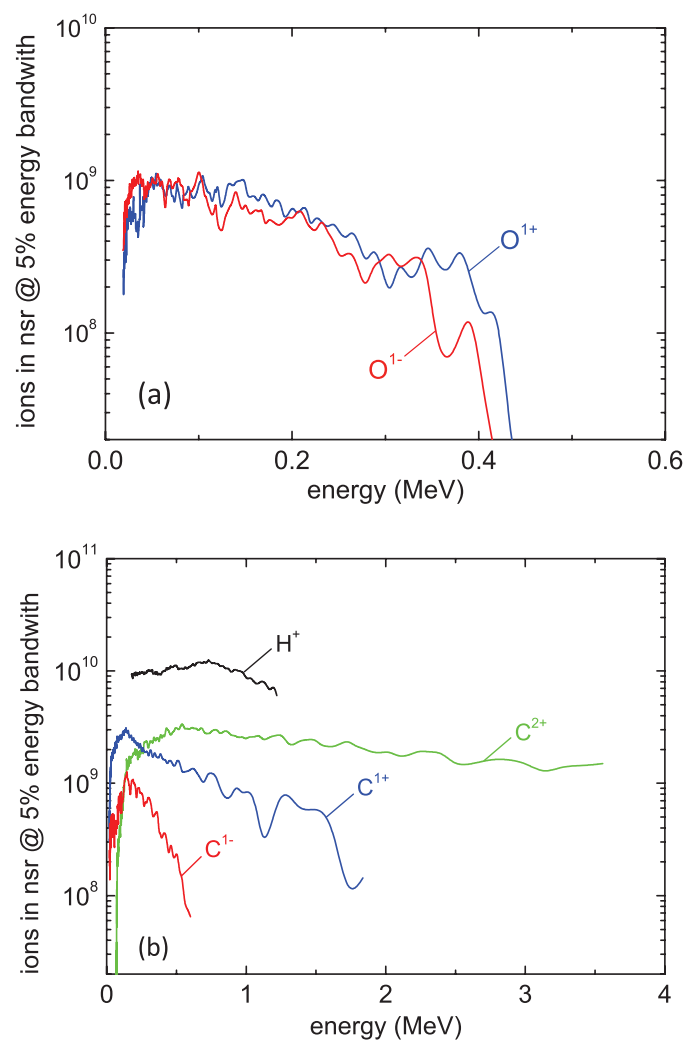

FIG. 5. Ion spectra accelerated from ethanol spray target, deduced from the digital CCD image of MCP-detector screen of the Thomson parabola spectrometer. (a) Negative and positive oxygen ion spectra; (b) negative and positive carbon ion and proton spectra.

$\mathrm{O}^{1-}$ ions and their maximum energies are much higher than in the water spray (compare Fig. 4 and Fig. 5(a)). As it was predicted by Particles-in-Cell (PIC) simulations ${ }^{9}$, for increased droplet diameter, the ion energies are increased. The higher average density of the ethanol spray as compared with water also favours a more effective formation of negative ions. $\mathrm{C}^{1-}$ ions are now observed from the ethanol spray, and the detection of protons with energies above $\mathrm{MeV}$ and of energetic $\mathrm{C}^{2+}$ ions also indicate more effective interaction conditions.

Acceleration of negative ions has been observed for the first time in this type of laser matter interaction experiments. The brightness of our negative ion source is extremely high, exceeding $10^{8} \mathrm{~A} \cdot \mathrm{cm}^{-2} \mathrm{sr}^{-1}$. This number results from an ion pulse duration of less than 10 ps and a current intensity exceeding $1 \mathrm{kA}$, with a source area $6 \times 70 \mu \mathrm{m}^{2}$ approximated to the transverse projection of the laser-plasma volume (focal spot diameter times confocal parameter). This is by far the brightest negative ion source reported.

There is a strong fundamental interest in negative ions due to the fact that electron correlation plays an important role in determining their structure and dynamics, ${ }^{17}$ which results in more efficient screening of the nucleus. Negative ions could provide an excellent tool for material processing applications due to their "charge-up free" property in implantation processes. ${ }^{18,19}$ Easy neutralization of an energetic beam of negative ions is exploited in accelerator technology, including injectors dedicated to heating of tokamak plasmas (e.g., the negative ion-based neutral beam injection (NBI) system in the 
International Thermonuclear Experimental Reactor (ITER)) and the next generation of particle accelerators such as European Spallation Source (ESS) and Spallation Neutron Source (SNS).

The efficient and reliable operation of negative ion sources is largely responsible for the productivity of these facilities. Additionally, for optimum applications, bright energetic negative ion sources are required. Laser-based negative ion acceleration can be an attractive option in the near future too, and may be useful overcome limitations imposed on ion pulse duration and emittance in currently available negative ion sources.

\section{SUMMARY}

In summary, ethanol $\left(\mathrm{C}_{2} \mathrm{H}_{5} \mathrm{OH}\right)$ was tested as an option to generate sprays of sub-micron size droplets with control- lable dimensions. The Mie scattering technique has been employed for their characterisation. The experiments with two different nozzles of different throat diameters, namely $470 \mu \mathrm{m}$ and $560 \mu \mathrm{m}$, showed that the size of the droplets in the spray is different: $(180 \pm 10) \mathrm{nm}$ and $(140 \pm 10) \mathrm{nm}$, correspondingly. However two different temperatures: 110 ${ }^{\circ} \mathrm{C}$ and $140{ }^{\circ} \mathrm{C}$ did not influence the droplet size.

Irradiation of water and ethanol sprays with ultra-intense $\left(5 \times 10^{19} \mathrm{~W} / \mathrm{cm}^{2}\right)$, ultra short (45 fs) laser pulses has demonstrated the capability of this devices as a bright negative ion sources. The results are very exciting and different spray parameters could show further interesting features and reveal the full potential of this targetry approach.

\section{APPENDIX: TABLE OF MIE SCATTERING FUNCTION FOR PARTICLES WITH REFRACTIVE INDEX 1.36}

TABLE I. The value of $i_{\perp} / \alpha^{3}$ as a function of scattering angle $(\theta)$ and size parameter $\alpha$ for $\mathrm{m}=1.36$. It should be noted that the function $i_{\perp}$ defined in Eq. (2) is actually equivalent to $i_{\perp} / \alpha^{3}$.

\begin{tabular}{|c|c|c|c|c|c|c|}
\hline \multirow{2}{*}{$\frac{\theta}{\text { Degree }}$} & \multicolumn{6}{|c|}{$\mathrm{i}_{\perp} / \alpha^{3}$} \\
\hline & $\alpha=1.3$ & $\alpha=1.4$ & $\alpha=1.5$ & $\alpha=1.6$ & $\alpha=1.7$ & $\alpha=1.8$ \\
\hline 0 & $2.5868479 \times 10^{-2}$ & $2.1847161 \times 10^{-2}$ & $1.6296347 \times 10^{-2}$ & $1.0330464 \times 10^{-2}$ & $5.3934101 \times 10^{-3}$ & $2.9375056 \times 10^{-3}$ \\
\hline 5 & $2.5970076 \times 10^{-2}$ & $2.1958424 \times 10^{-2}$ & $1.6405832 \times 10^{-2}$ & $1.0422393 \times 10^{-2}$ & $5.4491418 \times 10^{-3}$ & $2.9385213 \times 10^{-3}$ \\
\hline 10 & $2.6276014 \times 10^{-2}$ & $2.2294123 \times 10^{-2}$ & $1.6737186 \times 10^{-2}$ & $1.0702255 \times 10^{-2}$ & $5.6216589 \times 10^{-3}$ & $2.9480293 \times 10^{-3}$ \\
\hline 15 & $2.6789710 \times 10^{-2}$ & $2.2859959 \times 10^{-2}$ & $1.7299094 \times 10^{-2}$ & $1.1182283 \times 10^{-2}$ & $5.9269867 \times 10^{-3}$ & $2.9855405 \times 10^{-3}$ \\
\hline 20 & $2.7516779 \times 10^{-2}$ & $2.3665359 \times 10^{-2}$ & $1.8105981 \times 10^{-2}$ & $1.1882898 \times 10^{-2}$ & $6.3920199 \times 10^{-3}$ & $3.0839892 \times 10^{-3}$ \\
\hline 25 & $2.8464907 \times 10^{-2}$ & $2.4723340 \times 10^{-2}$ & $1.9177926 \times 10^{-2}$ & $1.2832740 \times 10^{-2}$ & $7.0547710 \times 10^{-3}$ & $3.2903197 \times 10^{-3}$ \\
\hline 30 & $2.9643671 \times 10^{-2}$ & $2.6050315 \times 10^{-2}$ & $2.0540507 \times 10^{-2}$ & $1.4068659 \times 10^{-2}$ & $7.9646534 \times 10^{-3}$ & $3.6662289 \times 10^{-3}$ \\
\hline 35 & $3.1064291 \times 10^{-2}$ & $2.7665815 \times 10^{-2}$ & $2.2224565 \times 10^{-2}$ & $1.5635631 \times 10^{-2}$ & $9.1827338 \times 10^{-3}$ & $4.2889815 \times 10^{-3}$ \\
\hline 40 & $3.2739303 \times 10^{-2}$ & $2.9592106 \times 10^{-2}$ & $2.4265824 \times 10^{-2}$ & $1.7586535 \times 10^{-2}$ & $1.0781870 \times 10^{-2}$ & $5.2521848 \times 10^{-3}$ \\
\hline 45 & $3.4682162 \times 10^{-2}$ & $3.1853682 \times 10^{-2}$ & $2.6704359 \times 10^{-2}$ & $1.9981722 \times 10^{-2}$ & $1.2846625 \times 10^{-2}$ & $6.6663765 \times 10^{-3}$ \\
\hline 50 & $3.6906737 \times 10^{-2}$ & $3.4476621 \times 10^{-2}$ & $2.9583851 \times 10^{-2}$ & $2.2888309 \times 10^{-2}$ & $1.5472839 \times 10^{-2}$ & $8.6592462 \times 10^{-3}$ \\
\hline 55 & $3.9426721 \times 10^{-2}$ & $3.7487765 \times 10^{-2}$ & $3.2950577 \times 10^{-2}$ & $2.6379096 \times 10^{-2}$ & $1.8766711 \times 10^{-2}$ & $1.1375276 \times 10^{-2}$ \\
\hline 60 & $4.2254935 \times 10^{-2}$ & $4.0913736 \times 10^{-2}$ & $3.6852121 \times 10^{-2}$ & $3.0531039 \times 10^{-2}$ & $2.2843249 \times 10^{-2}$ & $1.4974561 \times 10^{-2}$ \\
\hline 65 & $4.5402526 \times 10^{-2}$ & $4.4779747 \times 10^{-2}$ & $4.1335745 \times 10^{-2}$ & $3.5423200 \times 10^{-2}$ & $2.7823933 \times 10^{-2}$ & $1.9630554 \times 10^{-2}$ \\
\hline 70 & $4.8878080 \times 10^{-2}$ & $4.9108230 \times 10^{-2}$ & $4.6446414 \times 10^{-2}$ & $4.1134100 \times 10^{-2}$ & $3.3833463 \times 10^{-2}$ & $2.5526475 \times 10^{-2}$ \\
\hline 75 & $5.2686649 \times 10^{-2}$ & $5.3917285 \times 10^{-2}$ & $5.2224470 \times 10^{-2}$ & $4.7738454 \times 10^{-2}$ & $4.0995475 \times 10^{-2}$ & $3.2850154 \times 10^{-2}$ \\
\hline 80 & $5.6828716 \times 10^{-2}$ & $5.9218973 \times 10^{-2}$ & $5.8702983 \times 10^{-2}$ & $5.5303276 \times 10^{-2}$ & $4.9427169 \times 10^{-2}$ & $4.1787140 \times 10^{-2}$ \\
\hline 85 & $6.1299148 \times 10^{-2}$ & $6.5017503 \times 10^{-2}$ & $6.5904814 \times 10^{-2}$ & $6.3883412 \times 10^{-2}$ & $5.9232875 \times 10^{-2}$ & $5.2511978 \times 10^{-2}$ \\
\hline 90 & $6.6086151 \times 10^{-2}$ & $7.1307375 \times 10^{-2}$ & $7.3839507 \times 10^{-2}$ & $7.3516599 \times 10^{-2}$ & $7.0496641 \times 10^{-2}$ & $6.5177735 \times 10^{-2}$ \\
\hline 95 & $7.1170301 \times 10^{-2}$ & $7.8071565 \times 10^{-2}$ & $8.2500104 \times 10^{-2}$ & $8.4218233 \times 10^{-2}$ & $8.3274082 \times 10^{-2}$ & $7.9903971 \times 10^{-2}$ \\
\hline 100 & $7.6523702 \times 10^{-2}$ & $8.5279846 \times 10^{-2}$ & $9.1860081 \times 10^{-2}$ & $9.5976094 \times 10^{-2}$ & $9.7583820 \times 10^{-2}$ & $9.6763614 \times 10^{-2}$ \\
\hline 105 & $8.2109329 \times 10^{-2}$ & $9.2887366 \times 10^{-2}$ & $1.0187057 \times 10^{-1}$ & $1.0874533 \times 10^{-1}$ & $1.1339899 \times 10^{-1}$ & $1.1576939 \times 10^{-1}$ \\
\hline 110 & $8.7880634 \times 10^{-2}$ & $1.0083362 \times 10^{-1}$ & $1.1245809 \times 10^{-1}$ & $1.2244407 \times 10^{-1}$ & $1.3063940 \times 10^{-1}$ & $1.3686066 \times 10^{-1}$ \\
\hline 115 & $9.3781473 \times 10^{-2}$ & $1.0904190 \times 10^{-1}$ & $1.2352308 \times 10^{-1}$ & $1.3695012 \times 10^{-1}$ & $1.4916505 \times 10^{-1}$ & $1.5989182 \times 10^{-1}$ \\
\hline 120 & $9.9746412 \times 10^{-2}$ & $1.1741942 \times 10^{-1}$ & $1.3493938 \times 10^{-1}$ & $1.5209910 \times 10^{-1}$ & $1.6877167 \times 10^{-1}$ & $1.8462334 \times 10^{-1}$ \\
\hline 125 & $1.0570145 \times 10^{-1}$ & $1.2585814 \times 10^{-1}$ & $1.4655488 \times 10^{-1}$ & $1.6768446 \times 10^{-1}$ & $1.8918908 \times 10^{-1}$ & $2.1071677 \times 10^{-1}$ \\
\hline 130 & $1.1156520 \times 10^{-1}$ & $1.3423634 \times 10^{-1}$ & $1.5819360 \times 10^{-1}$ & $1.8345964 \times 10^{-1}$ & $2.1008298 \times 10^{-1}$ & $2.3773487 \times 10^{-1}$ \\
\hline 135 & $1.1725049 \times 10^{-1}$ & $1.4242113 \times 10^{-1}$ & $1.6965912 \times 10^{-1}$ & $1.9914276 \times 10^{-1}$ & $2.3106058 \times 10^{-1}$ & $2.6514773 \times 10^{-1}$ \\
\hline 140 & $1.2266645 \times 10^{-1}$ & $1.5027161 \times 10^{-1}$ & $1.8073945 \times 10^{-1}$ & $2.1442362 \times 10^{-1}$ & $2.5168039 \times 10^{-1}$ & $2.9234546 \times 10^{-1}$ \\
\hline 145 & $1.2772087 \times 10^{-1}$ & $1.5764287 \times 10^{-1}$ & $1.9121331 \times 10^{-1}$ & $2.2897318 \times 10^{-1}$ & $2.7146596 \times 10^{-1}$ & $3.1865752 \times 10^{-1}$ \\
\hline 150 & $1.3232292 \times 10^{-1}$ & $1.6439048 \times 10^{-1}$ & $2.0085739 \times 10^{-1}$ & $2.4245504 \times 10^{-1}$ & $2.8992336 \times 10^{-1}$ & $3.4337821 \times 10^{-1}$ \\
\hline 155 & $1.3638602 \times 10^{-1}$ & $1.7037539 \times 10^{-1}$ & $2.0945448 \times 10^{-1}$ & $2.5453841 \times 10^{-1}$ & $3.0656128 \times 10^{-1}$ & $3.6579699 \times 10^{-1}$ \\
\hline 160 & $1.3983072 \times 10^{-1}$ & $1.7546899 \times 10^{-1}$ & $2.1680196 \times 10^{-1}$ & $2.6491193 \times 10^{-1}$ & $3.2091300 \times 10^{-1}$ & $3.8523219 \times 10^{-1}$ \\
\hline 165 & $1.4258751 \times 10^{-1}$ & $1.7955801 \times 10^{-1}$ & $2.2272015 \times 10^{-1}$ & $2.7329756 \times 10^{-1}$ & $3.3255855 \times 10^{-1}$ & $4.0106563 \times 10^{-1}$ \\
\hline 170 & $1.4459937 \times 10^{-1}$ & $1.8254904 \times 10^{-1}$ & $2.2706009 \times 10^{-1}$ & $2.7946348 \times 10^{-1}$ & $3.4114582 \times 10^{-1}$ & $4.1277577 \times 10^{-1}$ \\
\hline 175 & $1.4582393 \times 10^{-1}$ & $1.8437240 \times 10^{-1}$ & $2.2971020 \times 10^{-1}$ & $2.8323534 \times 10^{-1}$ & $3.4640880 \times 10^{-1}$ & $4.1996693 \times 10^{-1}$ \\
\hline 180 & $1.4623505 \times 10^{-1}$ & $1.8498504 \times 10^{-1}$ & $2.3060137 \times 10^{-1}$ & $2.8450486 \times 10^{-1}$ & $3.4818187 \times 10^{-1}$ & $4.2239199 \times 10^{-1}$ \\
\hline
\end{tabular}




\section{ACKNOWLEDGMENT}

This work was supported by the Laser Lab Europe (Proposal Nos. MBI 001477 and MBI 001668), Transregio 18 (DFG), EPSRC (Grant No. EP/E035728/1) (LIBRA Consortium), and ELI-Beamlines (CZ.1.05/1.1.00/483/02.0061), Prague, Czech Republic. P.V.N. acknowledges the support of the World Class University program (R31-2008-000-100260 ) grant provided by the National Research Foundation (NRF) of Korea. We are also very thankful for excellent support of the MBI staff.

${ }^{1}$ T. Ditmire, T. Donnelly, A. M. Rubenchik, R. W. Falcone, and M. D. Perry, Phys. Rev. A 53, 3379 (1996).

${ }^{2}$ L. C. Mountford, R. A. Smith, and M. H. R. Hutchinson, Rev. Sci. Instrum. 69, 3780 (1998).

${ }^{3}$ S. Ter-Avetisyan, M. Schnürer, and P. V. Nickles, "Device and method for the creation of droplet targets," U.S. patent DE 10260376 A1 (2004).

${ }^{4}$ S. Ter-Avetisyan, M. Schnürer, H. Stiel, and P. V. Nickles, J. Phys. D 36, 2421 (2003)

${ }^{5}$ S. Ter-Avetisyan, M. Schnürer, D. Hilscher, U. Janke, S. Busch, P. V. Nickles, and W. Sandner, Phys. Plasmas 12, 012702 (2005).

${ }^{6}$ B. Ramakrishnan, M. Murakami, M. Borghesi, L. Ehrentraut, P. V. Nickles, M. Schnürer, S. Steinke, J. Psikal, V. Tikhonchuk, and S. Ter-Avetisyan, Phys. Plasmas 17, 083113 (2010).
${ }^{7}$ D. Habs, G. Pretzler, A. Pukhov, and J. Meyer-ter-Vehn, Prog. Part. Nucl. Phys. 46, 375 (2001).

${ }^{8}$ S. Ter-Avetsiyan, B. Ramakrishna, M. Borghesi, D. Doria, M. Zepf, G. Sarri, L. Ehrentraut, A. Andreev, P. V. Nickles, S. Steinke, W. Sandner, M. Schnürer, and V. Tikhonchuk, Appl. Phys. Lett. 99, 051501 (2011).

${ }^{9}$ S. Ter-Avetisyan, B. Ramakrishna, R. Prassad, M. Borghesi, P. V. Nickles, S. Steinke, M. Schnürer, K. I. Popov, L. Ramunno, N. V. Zmitrenko, and V. Yu. Bychenkov, Phys. Plasmas 19, 073112 (2012).

${ }^{10}$ O. F. Hagena and W. Obert, J. Chem. Phys. 56, 1793 (1972); O. F. Hagena, Surf. Sci. 106, 101 (1981); Rev. Sci. Instrum. 63, 2374 (1992).

${ }^{11}$ S. Ter-Avetisyan, B. Ramakrishna, D. Doria, R. Prasad, M. Borghesi, A. A. Andreev, S. Steinke, M. Schnürer, P. V. Nickles, and V. Tikhonchuk, Rev. Sci. Instrum. 83, 02A710 (2012).

${ }^{12}$ G. Mie, Ann. Phys. 25, 377 (1908).

${ }^{13}$ M. Kerker, The Scattering of Light (Academic, New York, 1969).

${ }^{14}$ H. C. Van de Hulst, Light Scattering by Small Particles (Dover, New York, 1981).

${ }^{15}$ H. H. Denman, W. Heller, and J. Pangonis, Angular Scattering Function for Spheres (Wayne State University Press, Detroit, 1966).

${ }^{16}$ C. F. Bohren and D. R. Huffman, Absorption and Scattering of Light by Small Particles (Wiley-Interscience, John Wiley \& Sons, Inc., 1983).

${ }^{17}$ U. Fano, Rep. Prog. Phys. 46, 97 (1983).

${ }^{18}$ J. Ishikawa, H. Tsuji, M. Mimura, S. Ikemura, and Y. Gotoh, Surf. Coat. Technol. 103/104, 173 (1998).

${ }^{19}$ J. Ishikawa et al., Nucl. Instrum. Methods Phys. Res. B 237, 422 (2005). 